\title{
Special issue: Biofunctional gels
}

\author{
Masato Ikeda ${ }^{1} \cdot$ Akinori Kuzuya $^{2} \cdot$ Michiya Matsusaki $^{3} \cdot K_{\text {Keiji Tanaka }}^{4}$ \\ Received: 28 April 2020 / Accepted: 28 April 2020 / Published online: 5 August 2020 \\ (c) The Society of Polymer Science, Japan 2020
}

Gels are attracting materials for a range of applications $[1,2]$. In particular, gels containing water (namely, hydrogel) or exhibiting stability under bio-relevant conditions have been finding fruitful biorelated applications [3]. The latest decade has been witnessed a rapid growth in research on gels exploring, for instance, polymer gels (chemical gels) with bio-orthogonal cross-linking and hydrogels (mostly physical gels) composed of biomolecules such as short peptides, proteins, (poly)saccharides, and nucleic acids.

In this special issue, to cover a wide range of research topic concerning such gels, we organized team composed of the editor-in-chief, an associate editor, and guest editors. We collected 10 Original Articles, 1 Note, 3 Focus Reviews, and 4 Reviews from (young) outstanding researchers from Japan, Korea, Germany, Portugal, USA, and Australia, which can provide the readers with an overview of this rapidly growing research field. Also, we would like to leave "biofunctional gels" not strictly defined and it to the authors as well as the readers, which may facilitate discussion or imagination to find their future applications.

Since 2012, Polymer Journal has published special issues on the related topics, e.g., self-assembled materials [4, 5], peptide materials [6], and biorelated materials [7]. As with recent special issues [8-15], we hope that this special issue is also valuable for the contemporary readers of this journal. Last, but certainly not least, we sincerely appreciate all authors and referees for their contribution to this issue.

Masato Ikeda

m_ikeda@gifu-u.ac.jp

1 Department of Chemistry and Biomolecular Science, Faculty of Engineering, Gifu University, Gifu, Japan

2 Department of Chemistry and Materials Engineering, Kansai University, Osaka, Japan

3 Department of Applied Chemistry, Graduate School of Engineering, Osaka University, Osaka, Japan

4 Department of Applied Chemistry and International Institute for Carbon-Neutral Energy Research (WPI-I2CNER), Kyushu University, Fukuoka, Japan

\section{Compliance with ethical standards}

Conflict of interest The authors declare that they have no conflict of interest.

Publisher's note Springer Nature remains neutral with regard to jurisdictional claims in published maps and institutional affiliations.

\section{References}

1. Ito K. Novel cross-linking concept of polymer network: synthesis, structure, and properties of slide-ring gels with freely movable junctions. Polym J. 2007;39:489-99.

2. Imran AB, Seki T, Takeoka Y. Recent advances in hydrogels in terms of fast stimuli responsiveness and superior mechanical performance. Polym J. 2010;42:839-51.

3. Ishihara K, Ueda T, Nakabayashi N. Preparation of phospholipid polymers and their properties as polymer hydrogel membranes. Polym J. 1990;22:355-60.

4. Kato T, Aoshima S, Kikuchi H. Special issue: self-assembled materials. Polym J. 2012;44:451.

5. Serizawa T, Shishido A, Luscombe CK, Kato T. Special issue: self-assembled structures and materials for accessing new functions. Polym J. 2018;50:539.

6. Venanzi M, Kimura S. Special issue: peptide materials. Polym J. 2013;45:467.

7. Serizawa T. Special issue: biorelated polymers and materials. Polym J. 2014;46:435.

8. Asakura T, Asano A. Preface to the special issue: NMR of polymers: recent advances and innovations. Polym J. 2012;44:733.

9. Kanaya T, Sakurai K, Takahara A. Special issue: application of quantum beams to polymer science and engineering. Polym J. 2013;45:2.

10. Kato T, Kikuchi H, Imai $H$. Special issue: fusion materials: creative development of materials and exploration of their function through molecular control. Polym J. 2015;47:77.

11. Tanaka K, Serizawa T, Chen W-C, Char K, Kato T. Special issue: polymer surfaces, interfaces and thin films. Polym J. 2016;48:323.

12. Yasuda T, Chen WC, Kato T. Special Issue: photo- and electrofunctional polymers and molecular assemblies. Polym J. 2017;49:1.

13. Kato T. 50th volume anniversary of Polymer Journal. Polym J. 2018;50:1.

14. Sakurai K, Takenaka M, Tanaka K. Special issue: cutting edge of scattering from softmaterials. Polym J. 2019;51:107.

15. Ouchi M, Luscombe CK, He J, Tanaka K. Special issue: precision polymer synthesis. Polym J. 2020;52:1. 